\title{
Performance e sacralidade nas exposições do MUQUIFU
}

\section{Performance and sacredness at MUQUIFU exhibitions}

\author{
Jezulino Lucio Mendes Braga \\ Mauro Luiz da Silva \\ DOI 10.265 I2/museologia.v9il 8.32795
}

\begin{abstract}
Resumo
Neste texto refletiremos sobre os enquadramentos, tradicionalmente impostos aos objetos dispostos nos museus, assim como analisaremos também a maneira como a interação objeto/museu acontece nos espaços comunitários, destacando-se aquilo que os distingue de outras formas de abordagens. Esta relação será analisada a partir de uma situação ocorrida no Museu dos Quilombos e Favelas Urbanos/BH (MUQUIFU), durante a preparação de uma festa do Congado no Aglomerado Santa Lúcia, no ano de 2018. Interessa-nos descrever e analisar como se deu a negociação por parte de um dos membros da Irmandade de Nossa Senhora do Rosário e de Santa Efigênia, localizada na Vila Estrela, bem como a gestão do Muquifu, especificamente a respeito de um instrumento musical denominado Caixa de Congo e Moçambiques.
\end{abstract}

\section{Palavras-chave}

Museu. Objeto. Musealização. Sagrado. Comunidade.

\begin{abstract}
In this text we will reflect on the guidelines, traditionally imposed on the objects displayed in museums, as well we will analyze also the way in which the interaction object / museum takes place in community spaces, highlighting what distinguishes them from other forms of approaches. This analyze will be done, based on a situation that occurred at the Museum of the Quilombos and Favelas Urbanos / BH (MUQUIFU), during the preparation of the Congado party in the Santa Lucia cluster, in the year of 2018. We are interested in describing and analyzing how one of the members of the Brotherhood of Nossa Senhora do Rosário and Santa Efigênia, located in Vila Estrela, negotiated with the managers of Muquifu the use of a musical instrument. We are also interested in understanding how the muquifu is managed, specifically in relation to this instrument, which is called Caixa de Congo and Moçambiques.
\end{abstract}

\section{Keywords}

Museum. Object. Musealization. Sacred. Community.

\section{Introdução}

Esse texto propõe um estudo de caso sobre a expografia do Museu dos Quilombos e Favelas Urbanos de Belo Horizonte/MG (Muquifu). Trata-se da exposição do objeto - utilizado em performances sonoras nas festas que homenageiam Nossa Senhora e Santa Efigênia - conhecido como Caixa de Congo e Moçambiques'. Esta caixa foi confeccionada em oficinas realizada na Guarda de Congo e Moçambiques "Treze de Maio" no bairro Concordia. As oficinas tinham por objetivo a troca de saberes e fazeres, inscritos nos rituais religiosos do congado mineiro².

Os instrumentos de percussão, respeitados e reverenciados por todos os integrantes do grupo, possuem grande força ritual. São confeccionados pelos mestres dos saberes do rosário, obedecendo um ritual de devoção, consti-

I A Caixa de Congo e Moçambiques é o principal instrumento musical do Congado e tem como característica fundamental o seu padrão rítmico e a acentuação realizada pelos caixeiros durante a execução. $O$ padrão rítmico desse instrumento repete-se regularmente, com as oscilações comuns existentes em todo o desempenho musical dos grupos de Congado.

2 Congado ou congada é uma prática cultural e religiosa afro-brasileira constituída de cantos e danças devocionais e coroação de reis e rainhas. 
Performance e sacralidade nas exposições do MUQUIFU

tuindo-se, dessa forma, em objetos do sagrado ${ }^{3}$. A referida caixa foi doada ao museu e hoje está em exposição junto com outros objetos que representam as práticas de devoção ancestral brasileira. Quando entrou no processo de musealização, a caixa foi colocada fora do alcance dos visitantes para que pudesse ser preservada. Em 2018, com a realização de uma festa de reinado na comunidade, local onde se situa a sede do museu, a caixa foi retirada da exposição retornando para a função na qual fora criada, ou seja, dar ritmo aos cantos e danças do congado.

A partir desse contexto, procuramos analisar, aqui, como se dá as formas de extroversão do sagrado no Muquifu, partindo do pressuposto que os projetos expográficos são negociados entre as equipes dos museus e os sujeitos que partilham experiências culturais representativas dos grupos que compõe a comunidade. A especificidade dos museus de comunidade está justamente na conciliação entre os interesses dos grupos que a representa e as funções destas instituições na sociedade. Dessa forma, a experiência que será narrada neste artigo demonstra que o objeto transita do universo museal para o universo ritual, colocando em xeque teorias e técnicas que envolvem o processo de musealização (BRULON: 2013:170).

Para além dos processos curatoriais, do interesse do público e da capacidade técnica, a dimensão simbólica revela que o museu é espelho de diversas categorias de representação social, entendido como processo capaz de assumir diferentes formas e apresentar-se de maneiras variadas, de acordo com os sistemas de valores priorizados em cada sociedade. $O$ museu pode ser reconhecido como um processo, porque admite subversões e desmontagens, principalmente quando tratamos de seu uso pela comunidade que o abriga. (SCHEINER, 2008: $4 I)$.

\section{A exposição do sagrado nos museus}

Uma das questões pertinentes na museologia contemporânea refere-se à musealização dos objetos sagrados. Considerando-se que o museu é um espaço laico, no qual objetos são expostos ao olhar, o ato de manipular e expor o sagrado requer protocolos diferenciados, uma vez que sua sacralidade está justamente no mistério que transcende a sua materialidade.

A museologia e o sagrado foram temas tratados no $41^{\circ}$ Simpósio Anual do ICOFOM, que aconteceu em Teerã em 2018. $O$ evento debateu aspectos relacionados à musealização do sagrado. Esse processo implica em um conjunto de desafios para a museologia, uma vez que a exposição do sagrado impõe cuidados específicos que perpassam, desde o manuseamento e armazenamento, até a comunicação da intangibilidade e dos significados polifônicos que lhes são implícitos. De acordo com François Mairesse, "El objetivo de este simposio es discutir los vínculos entre la museología y lo sagrado, especialmente a través de aquello que los une y lo que diferencia al museo del templo. (MAIRESSE: 2018:18)"

Uma das questões centrais debatidas nesse evento foram as perdas e ganhos da musealização do objeto sagrado, visto que o processo de musealização implica em dar novo significado a esses elementos, apartando-os, quase sempre,

3 Após a confecção estes objetos são confirmados com água benta, velas e preces para entrar no culto em adoração a Nossa Senhora. <https://www.youtube.com/watch?v=Mi2oUjrwOUw> acessado em $21 / 06 / 2020$ 
dos significados que possuem na vida social. De acordo com Brulon:

Tudo se passa como se a vida anterior à musealização deixasse de existir para que o objeto de museu possa "renascer" para um novo universo de significações. Nessa nova fase de sua existência são alterados, para além de sua função que deixa de ser utilitária e passa a ser interpretativa, os seus modos de se relacionar com os outros objetos e com os seres humanos que lhe dão sentido (BRULON: 2016:108).

No ato de ser musealizado, o objeto passa por uma seleção curatorial, tornando-se parte integrante da exposição e recebendo, dessa forma, elementos da cenografia e da apreciação estética, seja no visual, na forma, na composição, ou pelos efeitos da iluminação, efeitos de áudios, de vídeo, mobiliários e passa a ser representativo de um tipo de patrimônio cultural, eleito, tanto pela comunidade local, quanto pelo Estado-Nação.

Podemos dizer que antes das peças figurarem no museu elas são objetos e por isso constituem sistemas comunicacionais, através dos quais indivíduos, grupos e classes sociais emitem e recebem informações (GONÇALVES, 2007). $\mathrm{Na}$ passagem dos objetos cotidianos para objetos de museus, os primeiros sofrem acréscimos, passando, talvez, por subtrações e supressão de elementos narrativos que podem manter o sentido originário ou, simplesmente alterá-los completamente.

De acordo com Maria Isabel Roque, na avaliação do patrimônio sagrado, os objetos eram separados em tipologias que promoviam a pintura, a escultura e a ourivesaria. Aliada a esta classificação o museu impõe novo ritual, por meio dos protocolos exigidos para conservação e comunicação, distanciando o objeto do público visitante. Esse processo é definido pela autora como "artificação" do sagrado.

A autora faz uma análise da musealização do sagrado, a partir dos espólios das igrejas e de outros objetos que se encontram nos museus de Portugal e sugere que, na musealização dos objetos do sagrado, para além dos critérios patrimoniais, sejam consideradas as capacidades denotativas e conotativas de cada peça (ROQUE:20II).

Neste processo, materialidade e imaterialidade caminham juntas, pois a observação material começa a ser complementada por uma abordagem semiológica acerca da sua capacidade de representação:

O estudo das peças e, nomeadamente, o seu inventário passam a incluir a descrição iconográfica e simbólica, abrindo campos específicos para o registo de dados relativos ao patrimônio imaterial, como o culto ou a devoção inerentes às peças que descreve. (ROQUE, 20I I:|40).

Em qualquer tipologia de museus, que possua este tipo de coleção, é preciso romper com os protocolos engessados nas técnicas da museologia, investigando os significados atribuídos ao objeto na vida social, destacando, na documentação museológica, os atributos iconográficos e simbólicos, além de enfatizar seus aspectos imateriais. Dessa forma, é possível reposicionar as peças em uma cenografia que permita entender o culto e a devoção em que estão relacionadas.

Maria Isabel Roque propõe, igualmente, que a exposição de objetos sagrados nos museus possa relacionar materialidade à imaterialidade do religioso, em uma expografia que estabeleça relações semânticas com outros objetos e 
Performance e sacralidade nas exposições do MUQUIFU

temas sagrados, dentro de uma narrativa polissêmica e aberta à compreensão dos visitantes. Para a autora:

O objecto não vale por si próprio, mas em função das relações que estabelece com o conjunto em que se integra. Dado que este tipo de peças não tem as mesmas exigências em termos de conservação e segurança, isto significa que pode dispensar o habitual aparato expositivo e, literalmente, sair das vitrinas. Perfila-se, aqui, uma metodologia cenográfica, ou analógica, com particular eficácia no âmbito da museologia de religião (ROQUE, 20 I I:|4I).

Em museus de comunidade, como o que trataremos neste artigo, os processos de musealização tendem a recriar os contextos junto com os objetos em relações intercambiantes entre a representação e a vida social.As atividades pertinentes à conservação da coleção são substituídas pela conservação dos processos e práticas culturais aos quais os objetos pertenciam antes de entrar nos museus.

Estes museus recomendam que tais processos sejam construídos de forma colaborativa e participativa. Tomamos como exemplo a essa forma de abordagem a exposição de longa duração "Uma Rainha na Favela”, inaugurada em 2017 no Muquifu, cuja a curadoria é de Cleiton Gos e Felipe Mamutte: a exposição é uma homenagem às rainhas negras das guardas de Congado, moradoras das vilas e favelas, dentre elas Dona Maria Marta da Silva Martins (78 anos) que, por vários anos, fez parte da Guarda de Marujos de Nossa Senhora do Rosário e São Cosme e São Damião no Morro do Papagaio, onde foi coroada Rainha Perpétua de Santa Efigênia, juntamente com seu esposo, já falecido, Sr. Expedito, Rei Congo de São Benedito. O casal real saía em cortejo pelas ruas e becos do Aglomerado Santa Lúcia (ASL), sempre seguidos por sua Guarda de Congado (músicos e dançantes).

Por ocasião da montagem da exposição, um grupo formado por familiares e vizinhos da Dona Marta se organizou e contribuiu de forma colaborativa em todo o processo, desde a pesquisa, coleta de acervo até a montagem da expografia, experiência que foi registrada no catálogo Habemus Muquifu, como segue:

\begin{abstract}
Instalação dedicada à Dona Maria Marta da Silva Martins, Rainha Perpétua de Santa Efigênia, moradora da Vila Estrela, no Morro do Papagaio. Nascida em 1942, Dona Martinha é um exemplo de muIher, filha, mãe, esposa, guerreira, amiga, referência de amor e fé não apenas para seus familiares, mas para toda a comunidade da Vila Estrela. Os objetos, indumentárias, instrumentos musicais, objetos litúrgicos e imagens sacras que compõem essa instalação buscam recriar as igrejas dedicadas a Nossa Senhora do Rosário, mãe dos congadeiros e congadeiras. Uma Rainha na Favela tornou-se um espaço de acolhimento para outras rainhas que resistem ao tempo, ao silenciamento, ao preconceito e ao esquecimento (SILVA et all: 2019).
\end{abstract}

Durante a montagem da exposição todos participaram de forma colaborativa, na tomada de decisões, na concepção, também na confecção do cenário, que tem como fio condutor a ornamentação do teto da sala. A montagem do teto foi feita de forma artesanal e a equipe que cuidou dessa tarefa realizou uma pesquisa das cores que deveriam ser utilizadas, assim como procurou se informar sobre a técnica utilizada em outros Reinos do ASL e de outras guardas de Congado, as quais serviram de referência para expografia. 


\title{
O Museu de Quilombos e Favelas Urbanos - Muquifu
}

O Museu de Quilombos e Favelas Urbanos - Muquifu - é um museu brasileiro, localizado em Belo Horizonte-MG, inaugurado no dia 20/I I/20 I2, dia Nacional da Consciência Negra no Morro do Papagaio (ASL). O Muquifu organiza ações educativas e eventos culturais, expõe objetos que narram as histórias dos moradores das vilas e favelas, bem como dos Quilombos Urbanos. O Muquifu é um museu de base comunitária e atualmente é gerido por um coletivo e mantem uma rede de colaboradores nas escolas e universidades.

Para compreender a história de criação do Muquifu é preciso fazer um retorno ao mês de agosto do ano 2000 , quando um grupo de mulheres, juntamente com a direção da igreja católica local, reuniu-se para tratar sobre uma festa religiosa que seria realizada no dia 12 de outubro, data em que a Igreja local celebra a festa de Nossa Senhora Aparecida.

A reunião daquele mês de agosto buscava organizar atividades que marcassem aquela data, tais como: procissão, barraquinhas e missas. Foi nesse encontro de mulheres e religiosos que Dona Emerenciana, moradora da Vila Estrela, afirmou:

\begin{abstract}
A gente não pode fazer procissão não!! Estamos vivendo um período de muita violência! Aqui mesmo, bem perto da gente, uma senhora foi vítima de uma bala perdida. Mas não podemos ficar de braços cruzados, podemos fazer uma passeata pela paz. (informação verbal) $)^{4}$.
\end{abstract}

A partir desta fala os favelados passaram a organizar o que se tornou um dos principais eventos do ASL, a Caminhada pela Paz. No dia 12 de outubro de 2000, por volta das 17 horas, reuniram-se na porta da Capela da Vila Estrela, e partiram em caminhada pelo aglomerado. A caminhada teve por objetivo denunciar a ausência de políticas públicas que promovam a dignidade humana nas favelas da cidade.

Mesmo com a mobilização da comunidade o final daquele ano foi marcado por uma onda de violência no ASL. No dia 10 de dezembro, num domingo à tarde, um dia em que se comemorava a Declaração Universal dos Direitos Humanos, um policial foi baleado dentro de uma viatura, o que ocasionou a ocupação do Morro do Papagaio ao longo de 14 dias pelo efetivo da Policia Militar (PM). Por conta desse acontecimento, a força policial local cometeu diversos atos de abuso de autoridade, perseguições e práticas de tortura na busca pelo jovem que, supostamente, teria efetuado o disparo na direção da viatura, atingindo e matando o policial militar.As buscas e os atos de violência se intensificaram e um jovem negro foi executado no dia 24 de dezembro, na véspera do Natal. Esse jovem tinha o mesmo nome do suspeito de ter atirado no policial, mas sem ligação com o assassinato. Foi morto pelo fato de ser negro e morador de comunidade. Posteriormente o outro jovem negro suspeito de ter atirado no Tenente também foi assassinado, mas não houve testemunhas no inquérito ${ }^{5}$.

Diante dos fatos ocorridos, em dezembro de 2000 a comunidade instituiu uma Comissão de Paz que produziu um manifesto intitulado "Do tenente ao servente: quatorze dias de terror no Aglomerado Santa Lúcia"6. O documen-

4 Moradora Emerenciana, depoimento colhido pelos autores (2000)

5 Este caso não foi concluído e o inquérito foi encerrado.

6 No dia 22 de dezembro de 2000 diversas entidades de defesa dos direitos humanos e representantes da comunidade do Aglomerado Santa Lúcia reuniram-se com o comando de Policiamento da Capital para 
Performance e sacralidade nas exposições do MUQUIFU

to visava estabelecer uma comunicação direta com o alto comando da Polícia Militar de Minas Gerais.A comissão organizou também uma cartilha de Direitos Humanos, intitulada "Kit de Sobrevivência para Tempos de Exclusão"7.

Ainda nos anos 2000 o ASL entrou no projeto de reestruturação urbanística chamado Vila Viva. O objetivo principal do programa foi remover famílias em áreas consideradas de risco (ambiental, elétrico e geológico), abrir vias para o tráfego de veículos e, em alguns casos, transformar o espaço geográfico em parques ambientais. $O$ programa previu que apenas $40 \%$ dos moradores seriam reassentados em apartamentos na mesma região; os outros $60 \%$ deveriam aguardar, em esquema de escalas, indenizações por área construída ${ }^{8}$.

Em 2010 diferentes movimentos sociais assinaram um manifesto contra o programa, denominando-o de Vila-Morta. Esses movimentos questionavam os verdadeiros interesses do poder público quando demoliam vilas da Regional Centro-sul da capital, pois essas eram áreas de especulação imobiliária, portanto, despertando interesse do comércio imobiliário. Além disso, apesar da necessidade de reestruturação urbanística nessas vilas, outros bairros periféricos apresentavam problemas de infraestrutura ainda piores que os do aglomerados.

A remoção das famílias reforçou o desejo de se criar um espaço dentro do Aglomerado a fim de salvaguardar a memória e a história dessas famílias que passaram pelo processo de remoção'. Surgiu, a partir de então, a primeira iniciativa para a criação do museu na comunidade. Em um primeiro momento foi feita uma convocação para que os moradores partilhassem suas histórias por meio de objetos que poderiam ser doados ou emprestados. A equipe foi surpreendida pela quantidade de objetos tridimensionais, documentos, fotografias, utensílios que foram chegando ao museu.

Investiu-se em uma metodologia baseada na museologia social e comunitária, que considera mais o imaterial, para além do desejo de preservação dos objetos $^{10}$. A missão do museu é descrita como:

museu dos quilombos e favelas urbanos tem por missão a recoIha e/ou tutela dos bens tangíveis e intangíveis representativos da população do Aglomerado Santa Lúcia e de outras favelas e quilombos urbanos de Belo Horizonte, na busca por representatividade de sua cultura e diversidade, pesquisando, conservando e comuni-

cobrar uma atitude mais respeitosa na ocupação do Morro do Papagaio. Quando representantes da comunidade do Morro do Papagaio entregaram aos órgãos de imprensa um relatório sobre a violência policial naquela favela. (MEDEIROS, 2006, p.38).

7 Foram publicados 10 mil exemplares e, na contracapa de cada Kit os favelados tinham acesso a quatro exemplares da "Carteirinha de Cidadão". As carteirinhas deveriam ser recortadas e cada pessoa da família deveria portá-la consigo, para ser exibida em caso de uma revista policial. Foram 40 mil carteirinhas distribuídas no ASL.

8 O programa Vila Viva começou a ser discutido e elaborado no ano de 1994, abrangendo obras em seis vilas e aglomerados. Tais obras englobam modificações, melhorias e construções relacionadas à remoção de famílias das áreas ditas insalubres ou de risco, saneamento, construção de novas unidades habitacionais padronizadas, reestruturação das vias de circulação e do sistema viário, urbanização de becos, implantação de áreas de lazer, incluindo parques, praças e centros esportivos e, por fim, a erradicação das áreas que oferecem risco de desmoronamento/deslizamento de encostas e/ou risco de enchentes.

9 Entre os organizadores do museu devem ser citados os museólogos José Augusto, Dalva Pereira e Luciana Horta, que chegaram ao museu para desenvolverem seus estágios acadêmicos. Mesmo antes da inauguração do Muquifu aproximaram-se diversos moradores, que participaram e ainda participam do museu:Alexandro, Lourdinha, Magda, Maria Rodrigues, Mariana, Catharina, Ronaldo, Rosarinho, Geraldinha, Afonso, Wilson entre outros.

10 Insiste-se nessa orientação para que, no momento da doação, seja identificado a quem pertence cada coleção e/ou cada objeto, documento, fotografia. 
cando este patrimônio, como fator essencial na luta por inclusão social, contra o racismo e pelos direitos básicos da população negra e pobre, garantido-lhe o direito a sua história e memória e com consequência o aumento da sua auto estima. (PINTO, 20I4:I0).

Pelo que vimos, o museu é experiência intrinsecamente vinculada ao histórico de lutas políticas e à organização social da comunidade local. Entendemos que os museus comunitários são continuadores dessa luta e podem criar novas experiências de transformação social junto às futuras gerações.

O nome do museu vincula-se as lutas históricas de resistência da população negra que se refugiava nos quilombos. De acordo com Arruti:

\begin{abstract}
O uso metafórico dos quilombos tradicionais está motivado pelos efeitos políticos decorrentes da adoção do termo remanescentes na legislação relativa a grupos indígenas e negros rurais, assim como baseado em literatura histórica e etnográfica, nos limites analíticos e teóricos da polarização, corrente na literatura de ciências sociais no Brasil, entre os classificadores raça e etnia (ARRUTI, 1997:38).
\end{abstract}

Neste caso a utilização do termo não se refere a uma continuidade efetiva entre as favelas e os quilombos históricos, mas de (re)apropriação de um simbolismo de luta. Trata-se de pensar a força que o termo encerra para a história da população negra, que teve seus ancestrais escravizados por mais de trezentos anos no país e que, ainda hoje, luta contra as violências físicas e simbólicas a qual são submetidos.

Percebemos que o Museu em questão se apresenta como uma organização em processo que, conforme caracterizada por Hugues de Varine-Bohan (2005), é uma instituição diretamente ligada à dinâmica da comunidade à qual representa, ou seja, os temas expositivos, as ações educativas e os eventos estão em processo direto com as transformações comunitárias, e/ou com o acervo de problemas (VARINE-BOHAN, 2005:189).

Para Kelly Freitas (2016) seria complexo afirmar que o Muquifu representa todos os moradores do Morro do Papagaio, pois:

Oficialmente são mais de 30 mil habitantes, divididos em grupos com culturas, religiões, condições econômicas e habitacionais diferentes. Não há homogeneidade ou um tipo de morador ideal. $\mathrm{O}$ que há é uma multiplicidade de pessoas e culturas (FREITAS, 2016: 87).

No entanto, de acordo com a autora, existe uma narrativa comum potencializada pelos objetos em exposição, que representam a luta por uma condição de existência com características comuns a outras várias ocupações pelo território brasileiro, muitas delas alijadas de direitos básicos como: saúde, saneamento básico, iluminação pública e segurança. De acordo com a autora:

$\mathrm{Na}$ contramão da representação museal e imagética baseada no colonialismo português no Muquifu não há objetos de tortura ou suplícios para representar a vida dos pobres e dos negros moradores de vilas, favelas e aglomerados (FREITAS, 2016:96).

As imagens dos homens negros e das mulheres negras estão representadas na diversidade de práticas culturais vivas, na herança de conhecimentos tradicionais e populares, na luta pelos direitos culturais, sobretudo na reivindicação do direto à cidade. A atual sede do museu encontra-se na fronteira entre 


\title{
Performance e sacralidade nas exposições do MUQUIFU
}

a comunidade do aglomerado e um bairro de classe média da cidade de Belo Horizonte, ou seja, a instituição localiza-se exatamente no ponto onde a paisagem da cidade começa a mudar, quando os prédios altos dão lugar aos barracos e as casas espalhadas pela topografia do morro.

A exposição foi remontada nesse espaço expositivo anexo da lgreja das Santas Pretas. Na nova sede foi incorporada uma coleção de objetos religiosos, pertencentes a Igreja Católica, além de objetos de outras religiões, praticadas pelos moradores do aglomerado. Além disso, as paredes da Capela receberam a pintura de afrescos que retratam as sete dores e as sete alegrias vividas por Nossa Senhora, intercaladas com cenas cotidianas do Morro e figuras de moradoras e moradores que são emblemáticas, na e para história do local. As esculturas sacras, os santos pretos, os objetos litúrgicos, assim como os painéis pintados na igreja, passaram a integrar o espaço expositivo do Muquifu.

No Muquifu a relação empática da comunidade com os objetos, documentos e coleções provocou uma situação que nos incitou a discutir neste artigo: trata-se da doação de uma Caixa de Congo e Monçambiques, que foi ofertada ao Muquifu em 2017 e que, por certo período, esteve em exposição até ser reivindicada por um grupo de Congado da Vila Estrela.

\section{A Caixa de Congo e Moçambiques: propriedade compartilhada}

Em setembro de 2017, aconteceu uma Mesa Redonda, que teve como objetivo o debate sobre a religiosidade afro-brasileira representada em objetos expostos no museu. Nessa mesa, Thaíse Valentim Madeira" falou sobre as formas de sociabilidade e organização desses grupos. Segundo a palestrante, as guardas

\begin{abstract}
[....] trabalham em função das festas do Rosário, que cumprem uma função social, política e econômica. Constituem-se como um lugar de encontro e construção identitária, ao mesmo tempo em que é um espaço de disputa de poder e reconhecimento. Percebemos como os Reinados encontraram nas festas as vias de transmissão de suas ideias, valores e crenças, saindo do obscurantismo ao qual eles foram subjugados ao longo da história (Gravação e transcrição dos autores, HD 60').
\end{abstract}

A fala da participante aponta para uma continuidade histórica entre as festas contemporâneas e as práticas culturais das irmandades religiosas do século XVIII que, para além da devoção aos santos católicos, eram espaços de sociabilidade, ajuda mútua e disputa política. No universo político e social da América Portuguesa,

[....] as irmandades parecem ter funcionado como meios de afirmação cultural, embora, do ponto de vista das classes dirigentes, essas segmentações tenham sido interessantes para manter as rivalidades étnicas entre os negros e, com isso, evitar suas perigosas alianças. (LUZ, 2016:133)

As referidas festas constituíam-se como uma das principais atividades de afirmação do status político das irmandades. Eram uma forma de devoção coletiva com intercâmbios entre o plano terrestre e espiritual, impregnadas de mis-

II Doutora em Comunicação Social (UFMG) e Mediação Cultural (Universidade Paris III Sorbonne Nouvelle). Trabalha com temáticas relacionadas à mediação cultural, dispositivos midiáticos, megaeventos, memória e patrimônio, diversidade cultural e tradições populares. 
ticismo religioso que faziam parte do catolicismo leigo dos séculos XVIII. Estas festas constituem-se, atualmente, como uma das principais práticas culturais da população negra em contextos rurais e nas periferias das cidades, especialmente as cidades mineiras.

No ano de 2018, na comunidade do ASL, a Irmandade de Nossa Senhora do Rosário e Santa Efigênia estava se preparando para realizar mais uma festa do Congado. Foi nesse evento que uma Caixa de Congo e Moçambiques, da coleção do museu, foi demandada por um dos integrantes da irmandade.

A Caixa fora doada ao museu pela Guarda de Congo e Moçambiques Treze de Maio $^{12}$ como uma contrapartida das oficinas de instrumentos realizadas em sua sede em 2017, por meio incentivo financeiro do Edital Descentra Cultura/20I4-BH. As oficinas tinham como objetivo provocar a memória dos Congadeiros, recuperando a forma tradicional de confeccionar instrumentos de percussão, que são utilizados tradicionalmente pelos grupos sendo eles: o Patangome $^{13}$, a Gunga ${ }^{14}$ e as Caixas de Congo e Moçambiques.

As oficinas foram coordenadas pelos Mestres da cultura tradicional, Srs Ricardo Casimiro Gasparino e Antônio Cassimiro das Dores Gasparino, que são capitães da Guarda Treze de Maio. Os coordenadores são detentores de conhecimentos relacionados a prática cultural e rituais afro-brasileiros. No momento da entrega dos instrumentos o Capitão Antônio Cassimiro deixou o seguinte depoimento:

\begin{abstract}
Olha, eu estou feliz e, ao mesmo tempo, estou triste com essa doação. Quando fizemos as oficinas o que nos motivava era pensar que o nosso trabalho iria trazer de volta a alegria, a festa, a música e a dança para alguma Guarda de Congado e que, finalmente, poderiam voltar a fazer suas homenagens a Nossa Senhora do Rosário [neste momento colocou a mão sobre o coração, num gesto reverente]. Eu pensei isso mesmo e, hoje, eu queria entregar essa Caixa pra alguém que fosse fazer ela cumprir sua missão. Eu não pensei que ela ficaria num museu, não pensei que o meu trabalho fosse terminar cheio de poeira, pendurado em alguma parede mofada, pros outros tirarem foto e tudo mais...Vocês não fiquem chateados comigo, mas eu penso isso mesmo. (informação verbal) ${ }^{15}$.
\end{abstract}

A fala de Antônio Cassimiro sinaliza que o museu pode ser interpretado como um lugar da morte dos objetos. Ao entrar nesses espaços o objeto deixaria de ter sua função original, pois que, seriam colocados em vitrines cemitérios, mumificados, empoeirados e com as marcas do abandono. É assim que o doador visualizou o destino da caixa.

O capitão admite que visitantes poderiam tirar fotos, pois o objeto estaria em um lugar de destaque, pendurado em uma parede, submetido ao ritual do museu como registro único na narrativa memorial construída pela curadoria. Mas sua expectativa era de que a caixa fosse usada no bailado devocional, acompanhando o entoar dos cantos e dando ritmo a dança dos congadeiros.

12 Guarda de Congo e Moçambique Treze de Maio - É uma das mais tradicionais representantes do Reinado. Localizada no Bairro Concórdia, na cidade de Belo Horizonte e no Estado de Minas Gerais.

I3 Patangome - É um instrumento musical o feito de latas ou calotas de carro, usado pelo congado na cultura popular, para marcação dos passos de dança e mudança de canto.

14 Gunga - É um chocalho feito de latinhas, contendo pequenas esferas de chumbo em seu interior e usado nos pés, sustentadas por correias de couro e que são amarradas no tornozelos, que ampliam a duração e o peso dos movimentos. As gungas representam as correntes que prendiam os escravos, nas quais eram colocados guizos para descobrir negros em fuga.

15 Depoimento de Antônio Cassimiro das Dores Gasparino (gravação, transcrição e grifos dos autores, HD 60', 2017) 
O objeto doado entrou na cadeia museológica, passando a compor o processo de identificação, descrição, registro, catalogação, documentação, numeração, etiquetagem, fotografia, inventário, higienização, conservação preventiva, acondicionamento e, finalmente, integrou-se à exposição. A artesania entra em um processo de musealização, e a caixa passa a compor a performance museal, ganhando o status de objeto de museu.

Ao entrar na exposição a caixa é sacralizada, do ponto de vista da teoria da museologia, pois se torna um objeto para informar, distrair, encantar, provocar sentidos próprios da relação do sujeito com as coisas no mundo.

Antônio Cassimiro reconhece a importância dos museus como nova morada para os objetos, onde serão vistos representando e valorizando a história do congado e da população negra:

\begin{abstract}
Mas eu estou feliz também, afinal de contas as pessoas vão ver a Caixa e vão saber um pouco mais sobre o que é o Congado, né? Museu é um lugar importante, né?! E o Congado é importante também. A gente merece estar aqui, no Muquifu. Prá que todo mundo saiba que o Povo Preto não desiste fácil, podem bater na nossa cabeça, podem acorrentar a gente, mas a gente insiste, a gente teima, a gente sobrevive. É isso: tô triste e tô feliz ao mesmo tempo. (Informação verbal) ${ }^{16}$
\end{abstract}

Neste caso, como objeto testemunho, fora da vida social, sua função agora é representar a história de práticas culturais afro-brasileiras (MAIRESSE \& DESVALLÉES:2013:70). O doador diz que o objeto, mesmo não servindo mais para alegrar a festas religiosas, pode testemunhar a resistência da população negra, que também deseja ter suas narrativas inscritas nos museus. E considera que os museus são instituições importantes, abertas ao público e que teria como função a partilha de memórias.

O Muquifu apresenta-se como um museu de comunidade e, portanto, as escolhas curatoriais são no sentido de proporcionar uma comunicação, na qual os objetos se relacionam com o real vivido, além dos significados produzidos a partir e através deles. Com a entrada da artesania no museu, os curadores resolveram colocá-la na relação com outros objetos no cenário que compõe a exposição “Uma Rainha na Favela”.

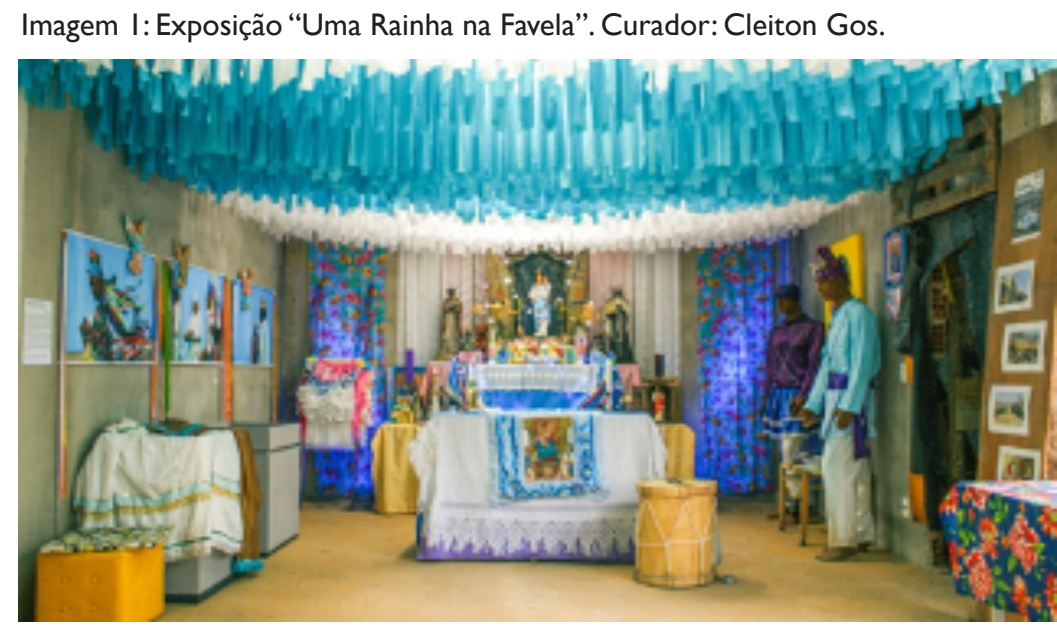

Foto:Alexsandro Trigger.Agora a caixa integra o altar.

16 Depoimento de Antônio Cassimiro das Dores Gasparino (gravação, transcrição e grifos dos autores, HD 60', 2017). 
A exposição aposta na performance de uma festa religiosa protagonizada por guardas de Congado e irmandades do Rosário, que são apresentadas através de muitas cores, luzes, manequins, objetos, trajes e imagens a devoção a Nossa Senhora do Rosário, que têm suas raízes nas festas da América Portuguesa no século XVIII.

Neste espaço da exposição o visitante é convidado a encontrar a experiências estéticas religiosas e a perfomance museal restitui o misticismo e alegria das festas:

Como nos rituais, a restituição revela que o que se mostra "determinante" e "fixo" são, de fato, processos, e não estados permanentes ou fatos na realidade social. Ao trazer para a vida do presente certos elementos, objetos, personagens, cenários e performances ligados ao passado, o museu restitui o público com possibilidade de reflexão sobre sua identidade coletiva, em processo no exato instante da visita. (BRULON, 20I3:I63)

Em atividades culturais que ocorrem no museu, os grupos de congado da região são convidados a dançar nesse espaço. Neste caso, a ressonância permite a aproximação com a exposição, em um intercâmbio de experiências em que a fruição é individual, mas a situação relacional destes momentos provoca imbricações de memórias, provocadas pelo contato visual com os objetos, potencializando os sons e as danças da prática cultural.

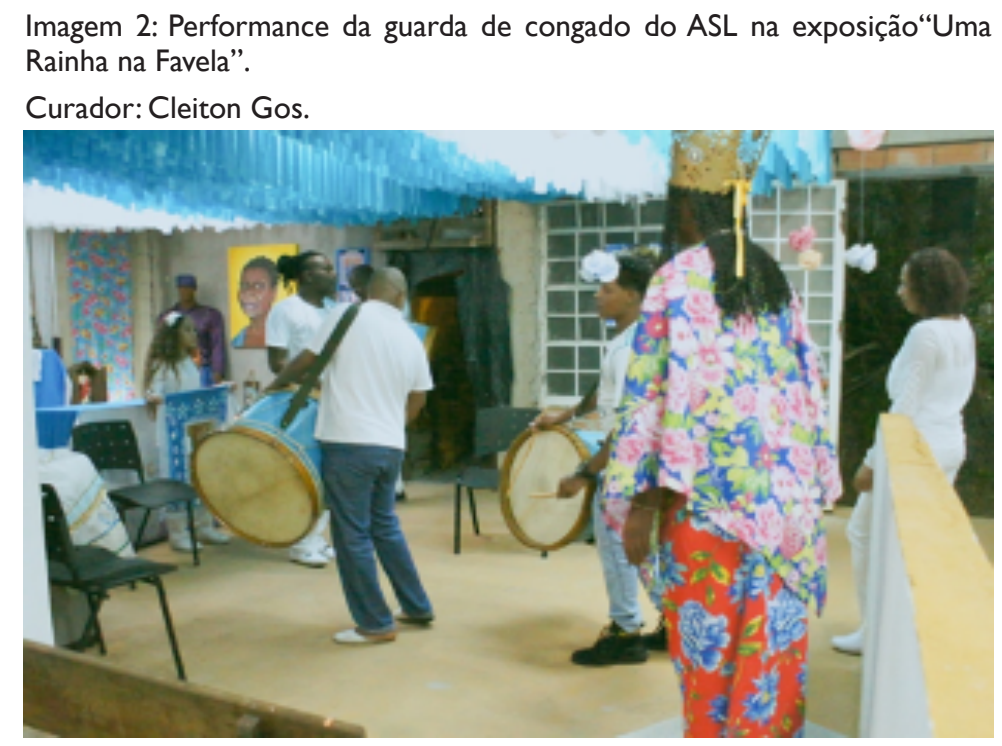

Foto:Alexsandro Trigger.

Percebemos que a curadoria usou analogias na elaboração da expografia. Nesse tipo de exposição o objeto é encenado em uma estrutura muito próxima à realidade. Mesmo sem textos explicativos, os visitantes não têm dificuldades em entender a sofisticação dos rituais e as práticas culturais da população negra representada no museu (ROQUE, 20II:I4I).

Em junho de 2018 o Coletivo Muquifu' ${ }^{17}$, que faz a gestão do museu, foi procurado para apoiar a realização de uma destas práticas culturais, as quais incluem as festividades em devoção a Nossa Senhora do Rosário e Santa Efigênia e que foi realizada por um grupo composto por familiares e amigos de Dona 
Performance e sacralidade nas exposições do MUQUIFU

Marta, homenageada na exposição.

Durante os preparativos para a festa surgiram muitas urgências e necessidades, por isso o grupo passou a buscar soluções criativas para cada situação enfrentada. Dentre essas dificuldades destacamos as mais complexas: (I) localizar uma igreja que aceitasse a celebração da Missa Conga; (2) confeccionar as bandeiras ${ }^{18}$ de Nossa Senhora do Rosário e de Santa Efigênia; (3) providenciar o mastro para as duas bandeiras; (4) identificar um local onde o mastro seria instalado; (5) conseguir um sacerdote que concordasse em presidir a celebração; (6) providenciar as fardas ${ }^{19}$ para todos os membros do grupo e refazer as vestes da Rainha; (7) restaurar o cetro e a coroa da Rainha; (8) preparar as refeições para todos os dias da festa e, principalmente, o almoço do encerramento; (9) ensaiar os cantos e as danças próprios do Congado; ( 10$)$ providenciar os instrumentos que seriam utilizados durante os ensaios e todos os dias da festa, em todos os cortejos e em todas as celebrações, da abertura à missa de encerramento.

O grupo acionou o museu quando precisou de uma Caixa de Congo e Moçambiques para dar seguimento às festividades. Como estratégia enviou ao Coletivo Muquifu um vídeo via aplicativo Whatsapp, no qual um dos músicos, Hélio Matias (45 anos), mais conhecido como Lú, utilizava um galão de plástico azul, uma espécie de recipiente para combustível, onde ele disse: "Olha aí pessoal, o nosso Congado voltou! Já começamos a ensaiar". (Vídeo de aplicativo de whatsapp)

Diante dessa provocação estratégica, o coletivo definiu por ampliar o apoio aos Congadeiros. Sugeriram, então, que eles buscassem a chave do museu, seguissem em direção ao segundo andar do prédio, onde se localizava a exposição, e retirassem a Caixa de Congo e Moçambiques que, até aquele momento, estava afixada em uma parede alta, intencionalmente distante dos visitantes mais afoitos que, por algum acaso, decidissem tocar o instrumento.

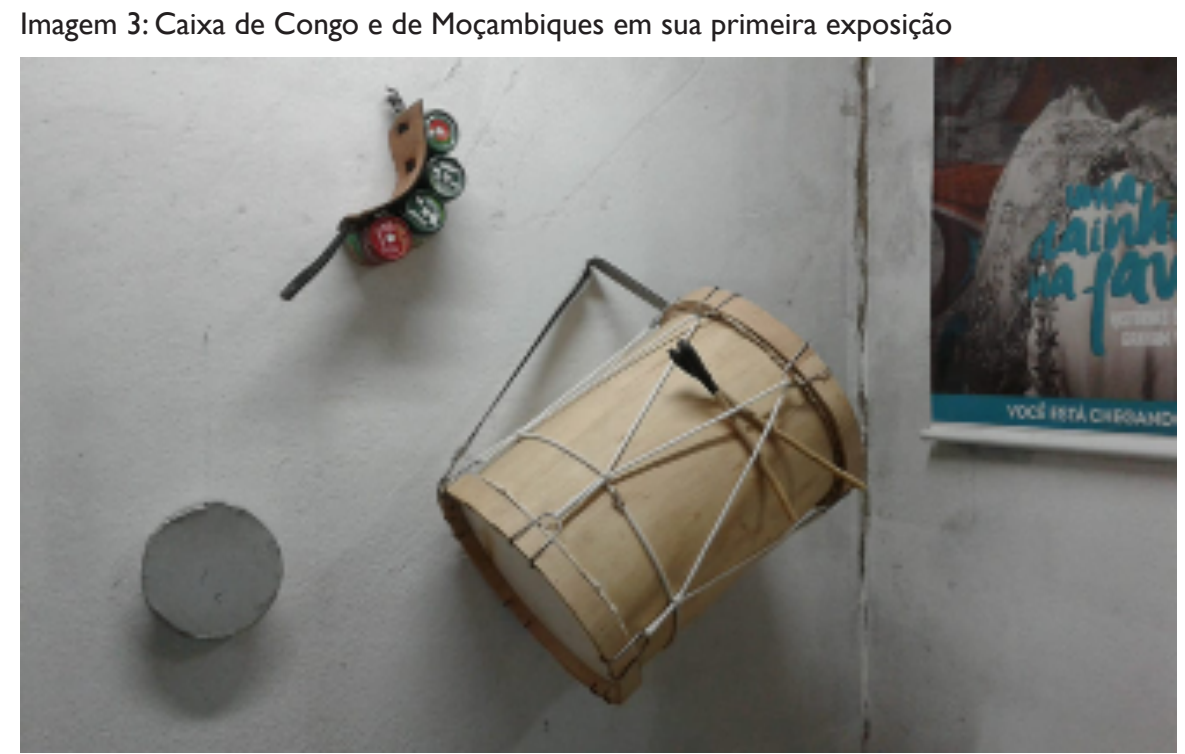

Foto: Cleiton Gos, 2019.

I8 Bandeira - As bandeiras representam cada terno e firmam a identidade do grupo, é a maneira do grupo celebrar a vitória em uma disputa é com a tomada da bandeira dos derrotados. Na festa a bandeira fundamenta a representatividade de todos os ternos.

19 Farda - É o traje utilizado pelos grupos de congado. O fardamento tradicional e composto por um saiote sobre a calça branca e turbante de lenço atado na fronte ou capacete cobrindo a cabeça. 
Como dissemos, o objeto sagrado doado ao museu foi confeccionado por mestres detentores de saberes tradicionais em uma oficina na Guarda de Congo e Moçambiques Treze de Maio. O fazer artesanal foi envolvido em um ritual de devoção que não pode ser desconsiderado nesta análise.

No Muquifu a Caixa passou pelo processo de musealização e podia ser vista, em um primeiro momento inacessível aos visitantes, compondo a exposição "Uma Rainha na Favela". A caixa foi confeccionada dentro de uma tradição religiosa e chegou ao museu como objeto sagrado, mesmo que não tenha sido usada em alguma festividade.

Por ocasião dos ensaios, bem como na festa em homenagem a Nossa Senhora do Rosário, a Caixa de Moçambiques deixou, mesmo que momentaneamente, sua vida museal e entrou para a prática cultural pulsante, tornando-se extensão do corpo dos dançantes da guarda, dando ritimo àquele corpo que dançava em louvor a Nossa Senhora, ao mesmo tempo em que entoava os cantos sagrados da manifestação.

O objeto assumiu a missão mencionada pelo doador Antônio Cassimiro, que desejava que a caixa não ficasse apenas empoeirando-se no museu, mas, também, que fosse envolvida na alegria da festa, como objeto pertencente ao ritual sagrado.

Terminada a festa em homenagem a Nossa Senhora do Rosário e Santa Efigênia os Congadeiros da Vila Estrela entraram em contato com o Coletivo Muquifu para agradecer a parceria estabelecida e, constrangidos, comunicaram que a Caixa de Congo e Moçambiques tinha sido danificada pela utilização contínua durante toda a festa, mas iriam providenciar o restauro a fim de levá-la de volta para a coleção do museu.

Após o restauro um dos integrantes do grupo se prontificou a retornar a Caixa para o mesmo local onde estava afixada. Entretanto, a curadoria decidiu que a Caixa não retornaria para a parede da sala de exposição mas, ficaria integrada ao cenário expositivo em outra performance, colocada próxima ao altar dedicado a Nossa Senhora e Santa Efigênia. Com esta decisão a curadoria possibilitou aos visitantes a oportunidade de tocá-la, encarnando o objeto, ao mesmo tempo em que ele os encarna, enquanto simulam os sons da caixa durante os rituais.

Os objetos relacionados ao sagrado, expostos nos museus, podem trazer de volta as sensibilidades provocadas no ato do culto ou da devoção de acordo com a performance expográfica planejada. De acordo com Brulon, objetos rituais ou sagrados chegam aos museus atravessando um processo de dessacralização para

[...] então, serem ressacralizados pela instituição que os irá exibir dentro de um novo contexto e segundo uma outra gramática social. Nesse sentido, a musealização pode equivaler a uma sacralização quando o museu coloca em prática um processo de regeneração simbólica do objeto. Esse se refere a uma tentativa de se recriar a força ritual do objeto, inserindo-o em uma performance museal. (BRULON,20।3:172)

Esta foi a escolha da curadoria ao expor o objeto sagrado em diálogo com outros objetos de devoção constituindo um altar que pode ser lido de diferentes formas pelos visitantes. 
Performance e sacralidade nas exposições do MUQUIFU

Considerações finais

A saída da Caixa de Congo e Moçambiques da exposição museal para entrar na vida pulsante da festa de Nossa Senhora do Rosário e Santa Efigênia levou a curadoria a dar novo sentido ao objeto sagrado, reforçando uma concepção de museologia singular em que a preservação dos objetos materiais está intimamente ligada aos processos culturais da comunidade. A comunidade foi interferente nas ações curatoriais, a partir do momento em que reinvindicou a caixa para seus festejos.

No Muquifu as fronteiras entre o sagrado e o laico não estão delimitadas. Os visitantes entram no museu pela Capela das Santas Pretas, onde foram pintados afrescos que contam a história da comunidade, intercambiados com narrativas bíblicas e onde está uma coleção de objetos litúrgicos. $O$ espaço laico do museu é acionado por outra porta, na qual estão as exposições de objetos doados pela comunidade. No segundo andar, novamente, os visitantes chegam a um esquema de fruição em nichos expositivos, em que a fé e tradição religiosa estão representadas e podem ver a Caixa próxima ao altar, colocada sem qualquer suporte expositivo.

Neste museu as categorias em que poderiam ser enquadradas os objetos sagrados são confrontadas com o universo simbólico e cultural dos sujeitos, que reivindicam suas narrativas para além da materialidade da exposição. As narrativas não são uma tela fixa para a leitura dos visitantes, mas são construídas nas práticas culturais, assim como no encontro da comunidade com suas memórias.Aqui o que vale é a performance, na qual o objeto sagrado é inserido e não as informações que podem ser extraídas dele. Não existem textos em plotagens e legendas. $O$ que há é uma cenografia que se fez por analogia aos altares em Igrejas e galpões das guardas de congado.

\section{Referências}

ARRUTI, José Maurício. Mocambo: antropologia e história do processo de formação quilombola. Bauru, SP: EDUSC, 2006.

BRULON, Bruno. Re-interpretando os objetos de museu: da classificação ao devir. Campinas: Transinformação. v. 28, n. I, p. I07-I I4, jan. 2016.

Da artificação do sagrado nos museus: entre o teatro e a sacralidade. São Paulo: Anais do Museu Paulista. v.2 I. n.2, p I55-I75. Dez 2013.

DESVALLÉES,André; MAIRESSE, François; SOARES, Bruno Brulon; CURY, Marília Xavier. Conceitos-chave de Museologia. [S.I: s.n.], 2013.

FREITAS, Kelly Amaral de. As forças culturais dos museus de quilombos e favelas urbanos e o poder da ressonância dos objetos biográficos. Dissertação de mestrado, I82f. Universidade do Estado de Minas Gerais, Belo Horizonte, 2016.

GODELIER, Maurice. Au fondement des sociétés humaines. Ce que nous apprend l'anthropologie. Paris:Albin Michel. Idées, 2007. 
LIMA Filho, Manuel;ABREU, Regina;ATHIAS, Renato;. (orgs.). Museus e Atores Sociais: Perspectivas Antropológicas. Recife: Editora UFPE/ABA Publicações, 2016. $290 \mathrm{p}$.

LUZ, Itacir Marques da. Irmandade e educabilidade: um olhar sobre os arranjos associativos negros em pernambuco na primeira metade do século XIX. Educ. rev.[online]., vol.32, n.3, pp.I 19-142, 2016.

MAIRESSE, François. La museología y lo sagrado. In: La museologia y lo sagrado. Materiales para una discussión. Paris: ICOFOM, p. I70-174, 2018.

MOLES, Abraham. Teoria dos Objetos. Rio de Janeiro: Edições Tempo Brasileiro, I89p, 1988.

PEARCE, Susan M. Objects as meaning; or narrating the past. In: PEARCE, Susan M. (Ed.) Interpreting objects and collections. Lond and New York: Routledge, p. 192, 2005.

POMIAN, Krzysztof. Coleção. Enciclopédia Einaudi, vol. I. Memória-História. Porto: Imprensa Nacional / Casa da Moeda, 1984.

ROQUE, Maria Isabel.A exposição do sagrado no museu. Comunicação \& Cultura [online] n.o II, Pp. I 29 - 146, 201 I.

SILVA, Mauro Luiz (Org.). HABEMUS MUQUIFU (Catálogo). Belo Horizonte, MG: Editora Marginália Comunicação, 66 pp. 2019.

VAN DER POEL, Francisco. Congado: origens e identidade. Disponível em <http://www.religiosidadepopular.uaivip.com.br/congadorigem.htm> acesso em 20 de janeiro de 2020. 